\title{
The Antioxidant and Hepatoprotective Effect of Alcoholic Extract of Ginger Against the Cisplatin- induced Oxidative Stress in Rats
}

\author{
Ilyad Eissa Beagloo', Mohammad Reza Valilu' ${ }^{2}$, Mehrnaz Motiei ${ }^{3}$, Mahdi Rahbar ${ }^{4}$ and \\ Amir Hejazi ${ }^{5 *}$
}

${ }^{1}$ Department of Pharmacology, Iran

${ }^{2}$ Department Veterinary pathology, Iran

${ }^{3}$ Department of Prosthodontics, Iran

${ }^{4}$ Department of Operative and Esthetic Dentistry, Iran

${ }^{5}$ Department of Internal Diseases, Iran

*Corresponding author: Amir Hejazi, Department of Internal Diseases, School of Medicine, Tabriz University of Medical Sciences,

Daneshgah Street, Tariz, Iran

ARTICLE INFO
Received: ${ }^{-1}$ June 26, 2019
Published: ${ }^{-1}$ July 02, 2019
Citation: Ilyad Eisa B, Mohammad Reza
V, Mehrnaz M, Mahdi R, Amir H. The An-
tioxidant and Hepatoprotective Effect
of Alcoholic Extract of Ginger Against
the Cisplatin-induced Oxidative Stress
in Rats. Biomed J Sci \& Tech Res 19(2)-
2019. BJSTR. MS.ID.003283.

Keywords: Ginger Rhizome (GREE); Cisplatin; Oxidative Stress; Liver Antioxidants; Rats

\section{ABSTRACT}

Background and Objectives: Cisplatin is an anticancer drug and highly toxic for the liver when it is used in high doses. The antioxidant stresses play a part in the toxicity of cisplatin. Considering the antioxidant properties of ginger rhizome, the present study evaluated the antioxidant effects of alcoholic extract of ginger rhizome (GREE) against the oxidative stress induced by cisplatin in rats.

Materials and Methods: In this experimental study, 60 adult male rats (SD) were randomly divided into four groups including group 1 (control group), groups 2 and 4 (received $200 \mathrm{mg} / \mathrm{kg}$ of GREE for 10 days), groups 3 and 4 (received $7.5 \mathrm{mg} / \mathrm{kg}$ of cisplatin intraperitoneally at the tenth day), and groups 2 and 4 (received ginger for extra three days). Finally, Tissue surfaces of malondialdehyde (MDA), reduced glutathione (GSH) and activity of superoxide dismutase enzymes, catalase, glutathione peroxidase and glutathione reductase in the liver tissue homogenates were measured. Then, these results were accorded with histopathology results.

Results: In group 4, GREE decreased the amount of malondialdehyde $(\mathrm{P}<0.001)$ and increased the amount of liver antioxidant significantly. The histological changes were aligned with Enzymatic findings based on histopathological examinations.

Conclusion: By considering antioxidant properties, GREE protects the liver of rats against the cisplatin -induced oxidative stress.

\section{Introduction}

The oxidative stress results from the imbalance between the released radicals in body and antioxidant defective mechanisms. In living creatures, lipid peroxidation in the walls of living cells is considered as the major target of released radicals. In these circumstances, not only the wall structure and its function are effected, but also some products of oxidation such as malondialdehyde can react with biomolecules and have cytotoxic and genotoxic effects. Thus, high amount of released radicals plays a crucial role in pathogenesis of some diseases like, diabetes, cardiovascular diseases, cancer, aging and the like
[1]. Although the industrial antioxidants are widely used during recent years, most of these combinations are harmful to health $[2,3]$. Some evidence confirms the toxicity and malnutrition effects of industrial antioxidants such as butylated hydroxyanisole, butylated hydroxytoluene and tert-beta-hydroxy quinone on food products. In addition, the risk of liver damage and developing cancer in laboratory animals is the major disadvantage of industrial antioxidants $[3,4]$. In this regard, natural antioxidants mainly found in medical plants, fruit and vegetables are very popular among the consumers, which seem to prevent some diseases [2]. 
Since the plants are one of the richest sources of antioxidant, more studies are getting done in this regard [2] the antioxidantrich herbs can protect cells from oxidative damages [5]. Natural antioxidants increase the plasma antioxidant potential and decrease the number of diseases like cancer, cardiovascular diseases and stroke [6]. Secondary metabolites derived from herbs such as phenol and total flavonoid are highly potential to clean the released radicals in all parts of the plant like leaves, fruits, seeds, roots and peel [7]. Thus, with regard to the high prevalence of chronic and erosive diseases, it is logical to use herbs, especially those with phenol and total flavonoid, to provide required antioxidants for body. Ginger is a potential antioxidant which decreases the released radicals (6-gingerol \& shogaols) [8]. Ginger is considered as the rhizome of fresh or dried zingiber officinale and its medicinal usage dates back ancient times from the east of Asia to the tropical regions of Australia [9,10].

Ginger has dramatic effects on body such as pain relief, rheumatoid arthritis [11], anti-inflammation [11], anti-tumor $[11,12]$, antioxidant $[11,13]$, free radical removal $[11,14]$, menstrual stimulation and treatment of menstrual irregularities $[15,16]$, spermatogenesis [15] and sexual desire [16]. Gingneroles in ginger cause the removal of free radicals, anti-serotonergic, the inhibition of prostaglandin production and anti-inflammatory effects [17]. Further, the sesquiterpenes inhibit the production of free radicals [14]. Also, 6- gingerol has an inhibitory effect on xanthine oxidase system [18]. Ginger is a healthy herb with very few harmful effects [19]. Furthermore, it is introduced as one of the best detoxifying substance against alcohol abuse [20] and the toxicity induced by bromobenzene [21]. Additionally, cisplatin is regarded as one of the most important anticancer drugs which is widely used to treat various types of cancers. It involves a strong anti-cancer effect against a wide range of malignancies including ovarian, testis, neck, bladder, lung and other tumors resistant to cancer regimens [22].

Despite the beneficial effects of cisplatin on the treatment of cancer, this drug has toxic effects on kidney, nervous system and auditory system [23]. The cisplatin toxic effects on kidney are serious and used in a limited dose, and hydrotherapy and persistent prescription of diuretic drugs are suggested for detoxifying the kidney in case of its use in high doses [24].Hepatotoxicity appears in invasive therapeutic protocols which higher-dose cisplatin is used for inhibiting tumor. It is worth noting that when the lowerdose cisplatin is used frequently, its toxic effects on liver keep emerging [25]. In this regard, cisplatin-induced hepatotoxicity has not received a considerable attention and there are a few data about its mechanisms.

It has been reported that the oxidative stresses are induced by producing reactive oxygen species (ROS), weakening the antioxidant defense system including antioxidant enzymes and non-enzymatic molecule reduced glutathione (GSH) following the treatment with cisplatin [26]. In addition, disorders in the structure and function of mitochondria, the occurrence of apoptosis [27] and involvement of pre-infusion genes such as COX-2 and iNOS (inducible nitric oxide synthetase) may play a major role in the mechanism of cisplatin-induced hepatotoxicity [28]. A large number of studies have assessed the protective effects of various chemical combinations which mediate the toxic effects of cisplatin, but some chemoprotector combinations used for this purpose in therapeutic protocols mediate its anticancer effects and some others do not completely remove its toxic effects [29]. With regard to the beneficial therapeutic effects of ingredients in ginger, especially the antioxidant effects $[30,31]$, this herb seems to protect the liver against oxidative toxic effects of cisplatin. Thus, the present study aimed to assess the protective effect of alcoholic extract of ginger against the cisplatin-induced hepatotoxicity in rats.

\section{Materials and Methods}

The present study is experimental. The samples of this study included 60 adult male rate from the race of SD weighted $220 \pm 20$ grams and aged 8 weeks. One week before the study, they were treated for the purpose of environmental compatibility. Animals were maintained in polyethylene cages at $23 \pm 2{ }^{\circ} \mathrm{C}$ and $60 \%$ moisture with 12 hours lightness and 12 hours darkness and free to eat and drink. After seven days of environmental compatibility, rats were randomly divided into four groups of 15 including control healthy group (normal control; NC), treatment group (received ginger rhizome ethanolic extract, GREE), control treatment group (received toxicant control, Cis) and treatment group (received GREE + Cis). Groups 1 (NC) and 3 (Cis) received normal saline, group 2 (GREE) and 4 (GREE + Cis) received $200 \mathrm{mg} / \mathrm{kg}$ of ginger rhizome ethanolic extract in $10 \mathrm{ml} / \mathrm{kg}$ normal saline (26) for 10 consecutive days. On the 10th day of experiment, group 3 (Cis) and 4 (GREE + Cis) received $7.5 \mathrm{mg} / \mathrm{kg}$ of single-dose cisplatin in $10 \mathrm{ml} /$ kg normal saline (Sigma, Chemical Company, St. Louis, MO, U.S.A), group 1(NC) and group 2 (GREE) just received $10 \mathrm{ml} / \mathrm{kg}$ of normal saline intraperitoneally, and the gavage continued for extra 3 days in treatment groups [32].

\section{Preparation of Ginger Extract}

Hydroalcoholic extract of Ginger was dried and powdered at $-50^{\circ} \mathrm{C}$. A great deal of herbs was wetted and filtered by ethyl alcohol twice [33]. Then, the received alcoholic extract was concentrated by distilling machine in vacuum and decanted by chloroform. The obtained aqueous phase was dried under proper circumstances. The dried extract was dissolved in physiology serum and prepared for injecting the concentrated solution. The extract was kept in fridge at freezing temperature [34].

\section{Measurement of Antioxidant Activity}

While performing liver biopsies in rats for histopathologic studies, another part of liver was washed in cool saline and $10 \%$ homogenate in $1.15 \%$ potassium chloride. Homogenate was centrifuged with 700 rounds/minute at $4 \stackrel{\circ}{ } \mathrm{C}$ for 10 minutes. The 
floating solution was used for measuring the amount of lipid peroxidation (through measuring malondialdehyde), the activity of antioxidant enzymes of superoxide dismutase (SOD), catalase, Glutathione peroxidase (GPx), and glutathione reductase (GR).

Malondialdehyde, as a scale of lipid peroxidation, was measured in thiobarbituric acid reactive substances (TBARS) using Esterbauer and Cheesman's methods and the amount of TBARS was defined as nmol/mg protein [19].The activity of superoxide dismutase enzyme was evaluated using Nishikimi's method [35] and balanced by Kakkar's method [24]. Every activity of superoxide dismutase was determined as a concentration of enzymes required for preventing color production by $50 \%$ in 1 minute.The activity of catalase was evaluated using Claiborne's method [16] and based on hydrogen peroxide decomposition. The activity of glutathione peroxidase was evaluated using the method of Rotruck et al. [36] and based on $\mathrm{H} 2 \mathrm{O} 2+2 \mathrm{GSH}$ (reduced glutathione) $\rightarrow 2 \mathrm{H} 2 \mathrm{O}+$ GSSG (Glutathione oxide) and defined as $\mathrm{mmol} / \mathrm{min} / \mathrm{mg}$ protein. The activity of Glutathione reductase was measured using the method of Mohandas et al. and based on NADPH + H+ + GSSG $\rightarrow \mathrm{NADP}++$ 2GSH [37].

\section{Histopathological Studies}

At the end of the 13th day, all the rats were killed comfortably by cervical spine dislocation. The livers were extracted immediately from diaphragmatic left lobe of liver and placed in $10 \%$ buffer formalin for stabilization. In the next step, using the most common methods of tissue passage and the preparation of pathology sections, $5 \mu \mathrm{m}$ of cuts, one section from each 10 cuts, and totally three hematoxylin- and- eosin -stained sections from each sample were prepared. The amount of inflammation in portal area, liver necrosis, and infiltration of inflammatory cells in semi-quantitative scale was evaluated by Frei et al. The intensity of pathology was scaled from 0 to 4 (No damage: 0, Minimum damage: 1, Mild damage: 2, Average damage: 3, Severe damage: 4) [19]. All the scales with a magnification of $\times 100$ and 5 microscopic fields were randomly rated by using optical microscope, Nikon model (ECLIPSE E 200, made in Japan).

\section{Data Analysis}

Data were analyzed using SPSS 16 . The quantitative data were presented as Mean \pm SD and the significant difference between the groups were interpreted by one-way ANOVA and Tukey post hoc test $(\alpha=0.05)$. P-value $<0.05$ was considered as significant.

\section{Results}

\section{Antioxidant Factors}

As shown in Table 1, the amounts of antioxidant enzymes, glutathione, and malondialdehyde are not significantly different in NC and GREE groups, while in group 3 (Cis), cisplatin significantly decreased the amount of reduced glutathione and glutathione reductase enzyme, glutathione peroxidase, superoxide dismutase and catalase compared with the amount in group 1 (NC) $(\mathrm{P}<0.001)$. On the other hand, the amount of malondialdehyde increased significantly in this group $(\mathrm{P}<0.005)$. In group 4 (GREE + Cis), ginger rhizome extracts stop decreasing the amounts of reduced glutathione and superoxide dismutase enzymes, catalase, glutathione peroxidase and glutathione reductase induced by cisplatin. In addition, ginger stops increasing the amount of malondialdehyde since no significant difference was observed between this group and group $1(\mathrm{NC})$.

Table 1: Effect of alcohol extract of ginger rhizome on antioxidant activity of rats' liver in cisplatin-induced damage.

\begin{tabular}{|c|c|c|c|c|c|c|}
\hline Group & $\begin{array}{c}\text { GPx } \\
\text { (U/mg Protein) }\end{array}$ & $\begin{array}{c}\text { GR } \\
\text { (U/mg Protein) }\end{array}$ & $\begin{array}{c}\text { SOD } \\
\text { (U/mg Protein) }\end{array}$ & $\begin{array}{c}\text { Catalase } \\
\text { (U/mg Protein) }\end{array}$ & $\begin{array}{c}\text { GSH } \\
(\mu \mathrm{g} / \mathrm{mg} \text { Protein) }\end{array}$ & $\begin{array}{c}\text { MDA } \\
\text { (nmol/g Protein) }\end{array}$ \\
\hline $\mathrm{NC}$ & $12.1 \pm 8.6$ & $121.1 \pm 2.4$ & $17.0 \pm 8.3$ & $68.3 \pm 7.9$ & $9.0 \pm 8.2$ & $3.0 \pm 6.4$ \\
\hline GREE & $13.0 \pm 7.3$ & $117.3 \pm 5.8$ & $16.0 \pm 9.9$ & $64.4 \pm 5.11$ & $9.0 \pm 5.3$ & $3.0 \pm 5.8$ \\
\hline Cis & $6.0 \pm 9.5$ & $73.2 \pm 6.3$ & $11.0 \pm 2.2$ & $39.3 \pm 9.51$ & $4.0 \pm 3.9$ & $4.0 \pm 9.5$ \\
\hline GREE + Cis & $\begin{array}{c}11.0 \pm 7.9 \\
\odot \odot \odot\end{array}$ & $\begin{array}{c}115.2 \pm 1.6 \\
0 \odot \odot\end{array}$ & $\begin{array}{c}16.0 \pm 3.3 \\
00\end{array}$ & $\begin{array}{c}66.3 \pm 17.24 \\
0 \odot \odot\end{array}$ & $\begin{array}{l}7.0 \pm 3.4 \\
0 \odot \odot\end{array}$ & $\begin{array}{c}3.0 \pm 4.6 \\
00\end{array}$ \\
\hline
\end{tabular}

GPx: Glutathione peroxidase, GR: glutathione reductase, SOD: superoxide dismutase, GSH: reduced glutathione, MDA: malondialdehyde, NC: Normal Control, GREE: Hydroalcoholic Extract of Rhizome Ginger, Cis: Cisplatin **P<0.01, *** $\mathrm{P}<0.001, \odot \odot \mathrm{P}<0.01$ compared to control group, $\odot \odot \odot \mathrm{P}<0.001$ compared to cisplatin group

\section{Histopathological Results}

Lobular and cellular structure of rats' liver in group 1(NC) was healthy. However, in the rats' liver in group 3 (Cis), the scattered foci of necrosis in different parts of liver lobules, invasion of inflammatory cells with average infiltration around the central venous and congestive portal veins, interspace bleeding, and vacuolization of cytoplasm of liver cells were observed. In group 4 (GREE+Cis), treatment with ginger rhizome extracts dramatically prevented pathologic changes in rats' liver tissue and the only visible pathology was mild degenerative changes around the central venous. The overview was the same as control group.

Tables 2-4 indicate the quantitative observations of rats' liver tissue. 
Table 2: Effect of alcoholic extract of ginger rhizome on the amount of cisplatin-induced hepatocyte necrosis in rats' liver (induced by cisplatin).

\begin{tabular}{|c|c|c|c|c|}
\hline \multirow{2}{*}{$\begin{array}{c}\text { Amount of Hepatocyte } \\
\text { Necrosis }\end{array}$} & NC & GREE & Cis & Greatment Groups \\
\cline { 2 - 5 } & 15 & 15 & 0 & 9 \\
\hline 0 & 0 & 0 & 0 & 3 \\
\hline 1 & 0 & 0 & 2 & 0 \\
\hline 3 & 0 & 0 & 9 & 0 \\
\hline 4 & 0 & 0 & 4 & \\
\hline
\end{tabular}

0: No damage, 1: Minimum damage, 2: Mild damage, 3: Average damage, 4: Severe damage

NC: Normal Control, GREE: Alcoholic Extract of Rhizome Ginger, Cis: Cisplatin

Table 3: Effect of alcoholic extract of ginger rhizome on the amount of bleeding and inflammation in portal area of rats' liver tissue (induced by cisplatin).

\begin{tabular}{|c|c|c|c|c|}
\hline \multirow{2}{*}{$\begin{array}{c}\text { Amount Bleeding and } \\
\text { Inflammation on Portal } \\
\text { Area }\end{array}$} & NC & GREE & Cis & GREE + Cis \\
\cline { 2 - 5 } & 15 & 15 & 0 & 8 \\
\hline 0 & 0 & 0 & 0 & 4 \\
\hline 2 & 0 & 0 & 2 & 3 \\
\hline 3 & 0 & 0 & 7 & 0 \\
\hline 4 & 0 & 0 & 8 & \\
\hline
\end{tabular}

0: No damage, 1: Minimum damage, 2: Mild damage, 3: Average damage, 4: Severe damage

NC: Normal Control, GREE: Alcoholic Extract of Rhizome Ginger, Cis: Cisplatin

Table 4: Effect of alcohol extract of ginger rhizome on the amount of intravenous infiltration of inflammatory cells in rats' liver (induced by cisplatin).

\begin{tabular}{|c|c|c|c|c|}
\hline \multirow{2}{*}{$\begin{array}{c}\text { Amount of Intravenous } \\
\text { Infiltration of } \\
\text { Inflammatory Cells }\end{array}$} & NC & GREE & Cis & Treatment Groups \\
\cline { 2 - 5 } & 13 & 11 & 0 & 10 \\
\hline 0 & 2 & 4 & 0 & 2 \\
\hline 1 & 0 & 0 & 4 & 3 \\
\hline 3 & 0 & 0 & 8 & 0 \\
\hline 4 & 0 & 0 & 3 & 0 \\
\hline
\end{tabular}

0: No damage, 1: Minimum damage, 2: Mild damage, 3: Average damage, 4: Severe damage

NC: Normal Control, GREE: Alcoholic Extract of Rhizome Ginger, Cis: Cisplatin.

\section{Discussion}

Based on the results of histopathological studies, the prescription of cisplatin could cause pathological changes in liver tissue. However, treatment with ginger rhizome extracts dramatically prevented pathologic changes in rats' liver tissue. The above beneficial effects can result from the antioxidant effects and decreasing the oxidative stresses of ingredients in ginger extract [20]. The extract results in stabilizing the cell membranes and stopping the leakage of enzymes by preventing the lipid peroxidation [32]. In the present study, increasing MDA and decreasing GSH in liver tissue, following administering cisplatin, suggest that the oxidative stress from the released radicals is considered as one of the possible mechanisms in pathology of cisplatin-induced hepatotoxicity. The study of Partibh et al. [38] suggested lipid peroxidation and release of GSH in rats' liver following the treatment with cisplatin, which is consistent with the results of the present study [38].
Reduced glutathione (GSH) is regarded as a major part of nonenzymatic antioxidant systems and plays a pivotal role in controlling the toxic effects of cisplatin [22]. Thus, decreasing the level of GSH can be a direct factor in lipid peroxidation induced by cisplatin. The role of oxidative stress and intervention of reactive oxygen species (ROS) in pathogenesis of cisplatin-induced hepatotoxicity was proven [23]. Koc et al. investigated that cisplatin blocks the activity of superoxide dismutase enzymes, catalase and glutathione peroxidase, and increases the amount of malondialdehyde in rat's liver [28]. In the present study, some changes happened in antioxidant defense system and the amount of malondialdehyde in rats' liver following treatment with cisplatin, which is in line with consistent with their results. A decrease in the activity of superoxide dismutase is an index for pathology of liver cells. This enzyme is one of the major factors in enzymatic antioxidant defense system. Superoxide dismutase removes the anion superoxide through 
converting to hydrogen peroxide and consequently mediates its toxic effects [17].

In the present study, the amount of superoxide dismutase in cisplatin-treated rats dramatically decreased due to the formation of some anion superoxide. Consequently, the activity of enzymes removing the hydrogen peroxide such as catalase and glutathione peroxidase reduced in these rats. It seems that the inactivation of superoxide dismutase resulting from the increased anions of superoxide results in inactivating the enzymes of catalase and glutathione peroxidase. Analyzing the hydrogen peroxide, catalase protects the tissues against the hyperactive radials of hydroxyl. Thus, inactivating catalase results in some harmful effects from the radical of superoxide and peroxide [13]. Glutathione reductase is an enzyme for liver cytosol which plays a role in decreasing glutathione oxide (GSSG) as an ultimate product of activity of glutathione peroxide [25]. In the present study, using ginger rhizome extract stops decreasing superoxide dismutase, catalase, glutathione peroxidase induced by cisplatin, which may be related to the removal of radicals by extract protecting these enzymes.

Further, the treatment with cisplatin decreased the amount of glutathione peroxidase which caused glutathione reductase to access substrate. Thus, the activity of glutathione reductase decreases. It seems that ginger rhizome extract reactivates the glutathione reductase. Glutathione oxide is used to form reduced glutathione and increase the detoxification of active metabolites by conjugation with glutathione reduction. The results of the present study confirm the other reports about the antioxidant effects and removal of released radical in antioxidant herbal compounds. Ajith et al. focused on the protective effects of alcoholic extract of ginger root against cisplatin-induced nephrotoxicity and suggested that this extract plays a protective role against cisplatin by reducing the oxidative stresses. Additionally, it decreases the amount of malondialdehyde and increases the amount of reduced glutathione and the activity of antioxidant defense system enzymes like superoxide dismutase, catalase and glutathione peroxidase [5]. The results of their studies about the mechanism of alcoholic extract of ginger are consistent with those in the present study. In addition, they suggested that this herb can decrease the toxic effects of asthenophenone by improving the antioxidant functions [4]. They proved that ginger mediates the destructive effects resulting from doxorubicin on kidney tissues by decreasing the oxidant factors and increasing the antioxidant enzymes in kidney tissue [3]. Ansari et al. Reported that ginger decreases the oxidative stress resulting from isoproterenol of heart tissue in order to normalize the increased levels of catalase, superoxide dismutase, and glutathione [8]. The results are congruent with those in the present study.

They indicated that ginger can prevent lipid peroxidation induced by paraben [9]. As the released radicals intervenes inflammatory processes, Aimbire et al. suggested that ginger can decrease the sensitivity and inflammation of air paths resulting from inhaled polysaccharides. Based on the resulst, this plant functions with inhibition of COX and prevention of PGE2 and TXA2 [2]. In another study conducted by Franciscoa et al., ginger is full of phenolic antioxidants (flavonols) and hydroxycinnamic acid. These ingredients have direct and profound antioxidant effects and remove the released radicals effectively. Further, they can explain various genes involved in encoding metabolic enzymes which are effective in decreasing some diseases and disorders [20]. In general, ginger rhizome can be used as a medicinal herb to prevent cancer patients from cisplatin-induced oxidative hepatic damages. Furthermore, it can be used as a supplement and food additive due to its antioxidant properties or with cisplatin simultaneously. However, the present study did not focus on whether the extract of this herb can decrease the medical effects of cisplatin. In addition, neoplasia effects were not compared in the present study. Finally, it is recommended to study the effects of various doses of extract, molecular and cellular mechanisms in its pharmacological functions in further research.

\section{Conclusion}

Ginger rhizome protects the liver against the oxidative toxic effects of cisplatin through its antioxidant properties.

\section{References}

1. Nige E (2005) Cellular oxidative process in realation to renal disease. Nephrology 25(1): 13-22.

2. Wojcik M, Burzynska Pedziwiatr I, Wozniak LA (2010) A review of natural and synthetic antioxidants important for health and longevity. Curr Med Chem 17(28): 3262-3288.

3. Zhang J, Yuan K, Zhou WL, Zhou J, Yang P, et al. (2011) Studies on the active components and antioxidant activities of the extracts of Mimosa pudica Linn. From southern China. Pharmacogn Mag 7(25): 35-39.

4. Williams GM, Iatropoulos MJ, Whysner J (1999) Safety assessment of butylated hydroxyanisole and butylated hydroxyltoluene as antioxidant food additives. Food Chem Toxicol 37(9): 1027-1038.

5. Ajith TA, Nivitha V, Usha S (2007) alone and in combination with alphatocopherol protect the kidney against cisplatin-induced acute renal failure. Food Chem Toxicol 45(6): 921-927.

6. Prior RL, Cao G (2000) Antioxidant phytochemicals in fruits and vegetables. Diet and health implications Hortic Sci 35(4): 588-592.

7. Mathew S, Abraham TE (2006) In vitro antioxidant activity and scavenging effects of Cinnamomum verum leaf extract assayed by different methodologies. Food Chem Toxicol 44(2): 198-206.

8. Stoilova I, Krastanov A, Stoyanova A, Denev P, Gargova S, et al. (2007) Antioxidant activity of a ginger extract (Zingiberofficinale). Food Chem 102(3): 764-770

9. Gupta YK, Sharma M (2001) Reversal of pyrogallol-induced delay in gastric empting in rats by ginger (Zingiber officinale). Methods Find Exp Cline Pharmacol 23(9): 501-503.

10. Bhattaria S, Tran VH, Duke CC (2001) The stability of gingerol and shogaol in aqueous solutions. J Pharm Sci 90(10): 1658-1664.

11. Prasanna K, Kalpagam P, Nirmala K (2007) Alterations in antioxidant status of rats following intake of ginger through diet. Food chemistry 106(3): 991-996.

12. Pan MH, Hsieh MC, Kuo JM, Lai CS, Wu H, et al. (2008) 6-Shogaol induces apoptosis in human colorectal carcinoma cells via ROS production, caspase activation, and GADD 153 expression. Mol Nutr Food Res 52(5): 527-537.

13. Kavoli Haghighi M, Tooliat T (2002) Ginger. Journal of Medicinal Plants 1(1): $19-28$ 
14. Amin A, Hamza AA. (2006) Effects of Roselle and Ginger on cisplatininduced reproductive toxicity in rats. Asian J Androl 8(5): 607-612.

15. Mir Heydar H (1996) Herbal application in preventing and treatment of disease. Tehran; Islamic emission bureau.

16. Zargari A (1999) Medicinal Plants. Tehran University Press, Tehran p. 4.

17. Aimbire F, Penna SC, Rodrigues M, Rodrigues KC, Lopes-Martins RA, et al. (2007) Effect of hydroalcoholic extract of Zingiber officinalis rhizomes on LPS-induced rat airway hyperreactivity and lung inflammation. Prostaglandins Leukot Essent Fatty Acids 77(3-4):129-138.

18. Chang WS, Chang YH, Lu FJ, Chiang HC (1994) Inhibitory effects of phenolics on xanthine oxidase. Anticancer Res 14(2): 501-506.

19. Ali SS, Kasoju N, Luthra A, Singh A, Sharanabasava H, et al. (2008) Indian medicinal herbs as sources of antioxidants. Food Res. Int 41(1): 1-15.

20. Franciscoa M, Morenob DA, Carteaa ME, Ferreres F, García Viguera C, et al. (2009) Simultaneous identification of glucosinolates and phenolic compounds in a representative collection of vegetable Brassica rapa. J Chromatogr A 1216(38): 6611-6619.

21. El Sharaky AS, Newairy AA, Kamel MA, Eweda SM (2009) Protective effect of ginger extract against bromobenzene-induced hepatotoxicity in male rats. Food Chem. Toxicol 47(7): 1584-1590.

22. Hanigan MH, Devarajan P (2003) Cisplatin nephrotoxicity: Molecular mechanisms. Cancer Ther 1: 47-61.

23. Rabik CA, Dolan ME (2007) Molecular mechanisms of resistance and toxicity associated with platinating agents. Cancer Treat Rev 33(1): 9-23.

24. Kakkar P, Das B, Viswanathan PN (1984) A modified spectrophotometric assay of superoxide dismutase. Indian J Biochem Biophys 21(2): 130132.

25. Lee KJ, Choi JH, Khanal T, Hwang YP, Chung Y, et al. (2008) Protective effect of caffeic acid phenethyl ester against carbon tetrachlorideinduced hepatotoxicity in mice. Toxicology 248(1): 18-24.

26. Sadzuka Y, Shoji T, Takino Y (1992) Effect of cisplatin on the activities of enzymes which protect against lipid peroxidation. Biochem Pharmacol 43(8): 1872-1875.

27. Martins NM, Santos NA, Curti C, Bianchi ML, Santos AC, et al. (2008) Cisplatin induces mitochondrial oxidative stress with resultant energetic

ISSN: 2574-1241

DOI: 10.26717/BJSTR.2019.19.003283

Amir Hejazi. Biomed J Sci \& Tech Res

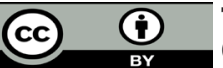

This work is licensed under Creative

Commons Attribution 4.0 License

Submission Link: https://biomedres.us/submit-manuscript.php metabolism impairment, membrane rigidification and apoptosis in rat liver. J Appl Toxicol 28(3): 337-344.

28. Kim SH, Hong KO, Chung WY, Hwang JK, Park KK, et al. (2004) Abrogation of cisplatin-induced hepatotoxicity in mice by xanthorrhizol is related to its effect on the regulation of genetranscription. Toxicol Appl Pharmacol 196(3): 346-355.

29. Aamdal S, Fodstad O, Pihl A (1987) Some procedures to reduce cisplatinum toxicity reduce antitumor activity. Cancer Treat Rev 14(3-4): 389-395.

30. Franciscoa M, Morenob DA, Carteaa ME, Ferreres F, García Viguera C, et al. (2009) Simultaneous identification of glucosinolates and phenolic compounds in a representative collection of vegetable Brassica rapa. J Chromatogr A 1216(38): 6611-6619.

31. Kim YH, Kim YW, Oh YJ, Back NI, Chung SA, et al. (2006) Protective effect of the ethanol extract of the roots of Brassica rapa on cisplatininduced nephrotoxicity in LLC-PK1 cells and rats. Biol Pharm Bull 29(12): 24362441.

32. (1998) Quality control methods for medicinal plant materials. Geneva, World Health Organization.

33. Yamahara J, Huang QR, Li YH, Xu L, Fujimura H, et al. (1991) Gastrointestinal motility enhancing effect of ginger and its active constituents. Chemical and pharmaceutical bulletin 38: 430-431.

34. Jung UJ, Baek NI, Chung HG, Bang MH, Jeong TS, et al. (2008) Effects of the ethanol extract of the roots of Brassica rapa on glucose and lipid metabolism in C57BL/KsJ-db/db mice. Clin Nutr 27(1): 158-167.

35. Nishikimi M, Rao NA, Yagi K (1972) The occurrence of superoxide anion in the reaction of reduced phenazine methosulphate and molecular oxygen. Biochem Biophys Res Commun 46(2): 849-854.

36. (1985) African pharmacopoeia, ( $1^{\text {st }}$ edn.). Lagos, Organization of African Unity, Scientific, Technical \& Research Commission 1.

37. Ajith TA, Hema U, Aswathy MS (2007) prevents acetaminophen-induced acute hepatotoxicity by enhancing hepaticantioxidant status. Food Chem Toxicol 45(11): 2267-2272.

38. Partibha R, Sameer R, Rataboli PV, Bhiwgade DA, Dhume CY, et al. (2006) Enzymatic studies of cisplatin induced oxidative stress in hepatic tissue of rats. Eur J Pharmacol 532(3): 290-293.

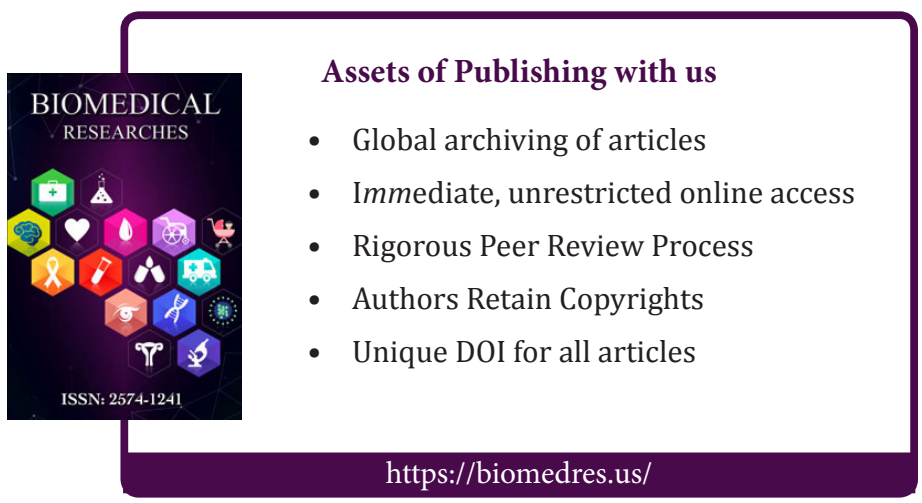

